\title{
COMO SÃO TRATAdOS OS DOENTES MENTAIS INFRATORES? Periculosidade, Medida de Segurança E REFORMA PSIQUIÁTRICA
}

\author{
Itana Viana ${ }^{(*)}$ \\ Luis Eugenio de Souza ${ }^{(* *)}$
}

\section{RESUMO}

Apesar dos avanços da reforma psiquiátrica no Brasil com o advento da Lei $n^{\circ} 10.216 / 2001$, os benefícios da desinstitucionalização progressiva e do tratamento em serviços substitutivos ainda não se estenderam às pessoas com transtorno mental que praticaram condutas delitivas e foram sentenciadas com a medida de segurança para tratamento compulsório em estabelecimento do sistema penitenciário - os Hospitais de Custódia e Tratamento Psiquiátrico (HCTP). Neste estudo, descreve-se a situação do HCTP da Bahia, no momento de uma intervenção do Ministério Público Estadual, e revisa-se a evolução histórica do tratamento dos doentes mentais infratores. A partir daí, discutem-se os obstáculos ao avanço da reforma psiquiátrica na área penal e as possibilidades de sua superação. Por fim, aponta-se a necessidade de fortalecimento de políticas sanitárias inclusivas e de mudanças nas leis e nas práticas judiciais, $\mathrm{O}$ que exige ainda a superação de preconceitos socialmente disseminados.

\section{Palavras-chave:}

Doentes Mentais; Periculosidade; Serviços de Saúde Mental.

\footnotetext{
(*) Mestre em Saúde Coletiva, Instituto de Saúde Coletiva, Universidade Federal da Bahia (ISC/UFBA). Promotora de Justiça, Ministério Público da Bahia. Salvador/BA - Brasil.

$\left.{ }^{* *}\right)$ Doutor em Saúde Pública, Universidade de Montreal (Canadá). Professor adjunto, Universidade Federal da Bahia (UFBA). Salvador/BA - Brasil. E-mail: < luiseugenio@ufba.br>. Texto recebido em 20.04.11. Aprovado em 16.07.11
} 


\section{ABSTRACT}

Despite the advances in mental health reform in Brazil with the advent of the Law $n$. 10.216/2001, the benefits of progressive deinstitutionalization and treatment in alternative services have not been extended to people with mental illness who have committed criminal behaviors and were sentenced to detention for compulsory treatment in an establishment of the prison system - the Hospitals of Custody and Psychiatric Treatment (HCTP). In this study, we describe the HCTP of the state of Bahia, in the moment of an intervention by the State Public Ministry, and we review the historical evolution of treatment of mentally ill offenders. Thereafter, we discuss the obstacles to the psychiatric reform in the penalty area and the possibilities of overcoming them. Finally, we point out the need to strengthen inclusive health policies and to change laws and judicial practices, which also requires the overcoming of prejudices socially widespread.

\section{Keywords:}

Dangerousness; Mental Health Service; Mentally III.

\section{INTRODUÇÃO}

Tem avançado no Brasil um processo de reforma psiquiátrica, baseada nos conceitos de dignidade humana e de inserção social das pessoas com transtornos mentais, que vem operando promissoras mudanças na assistência psiquiátrica. Busca-se o desenvolvimento de novas práticas de atenção à saúde mental, que se propõem a efetivar a desinstitucionalização, promovendo o fortalecimento de serviços alternativos inseridos no contexto descentralizado do Sistema Único de Saúde.

Todavia, à margem desses avanços, permanece um grupo de pessoas que compulsoriamente é submetido a tratamento: o das pessoas com transtornos mentais que cometeram delitos, que continuam custodiadas nas dependências de Hospitais de Custódia e Tratamento Psiquiátrico (HCTP), em condições sub-humanas, sem receber o tratamento adequado, inclusive sem a observância dos direitos fundamentais de cidadania previstos na legislação vigente. Por que essa exclusão? Como se explica que os doentes mentais infratores não sejam beneficiados com as mudanças nas práticas de atenção à saúde mental? Que obstáculos se interpõem ao avanço da reforma psiquiátrica nessa área?

O presente artigo tem como objetivo geral discutir essas questões. Para tanto, parte de uma situação concreta e descreve as condições atuais de tratamento dos doentes mentais infratores. Com base nessa descrição e em textos fundamentais da literatura especializada, busca identificar os obstáculos ao 
desenvolvimento dos princípios e das estratégias da reforma psiquiátrica nessa área e refletir sobre as possibilidades de superação destes obstáculos.

Como estratégia metodológica, realizou-se um estudo de caso no Hospital de Custódia e Tratamento Psiquiátrico da Bahia (HCTP-Ba). Além do estudo de caso, reviram-se os textos básicos sobre a evolução histórica do tratamento de doentes mentais infratores, incluindo a legislação antiga e a atual, nas áreas do direito penal e da saúde pública.

O artigo está organizado em três seções. Na primeira, são descritas as condições de tratamento dos doentes mentais infratores no HCTP-Ba. Na segunda seção, apresenta-se a revisão da literatura. Na terceira parte, são apontados os principais obstáculos ao processo da reforma psiquiátrica na área das pessoas com transtornos mentais que cometeram delitos, bem como discutidas as possibilidades de superação desses entraves. Por último, os comentários finais sintetizam a discussão.

\section{O TRATAMENTO DAS PESSOAS CUSTODIADAS NO HCTP-BAHIA}

O Hospital de Custódia e Tratamento Psiquiátrico da Bahia está localizado em região da periferia da cidade de Salvador, em um prédio construído no início do século XX para a instalação de uma penitenciária que ali funcionou durante muito tempo. É um prédio sombrio, com paredes de grande espessura e "pé direito" muito alto, em cujos corredores sem ventilação nem iluminação natural não se diferencia o dia da noite.

O HCTP é uma unidade prisional que integra o sistema penitenciário da Bahia, sob a administração da Secretaria Estadual de Justiça e Direitos Humanos ${ }^{1}$, destinada a receber, sob regime de internação e por determinação judicial para perícia, custódia e tratamento, indiciados, processados e sentenciados, suspeitos ou comprovadamente portadores de doença mental ou de desenvolvimento mental incompleto ou retardo, em regime fechado.

Em 2002, o Sindicato dos Servidores Penitenciários do Estado da Bahia fez uma representação ao Ministério Público Estadual, noticiando problemas relativos aos trabalhadores daquela instituição e irregularidades quanto às condições de salubridade e de cuidados dispensados aos internos do Hospital.

Vistoria realizada pelo Ministério Público, em fevereiro de 2003, encontrou inúmeros indícios da pertinência da representação feita pelo sindicato. Basta mencionar que, para uma capacidade de 280 leitos, havia, no momento da vistoria, 416 internos, sendo 376 homens e 40 mulheres.

(1) BAHIA, Secretaria de Justica, Direitos Humanos e Cidadania. Disponível em: <http://www.sjcdh. ba.gov.br/sap/unidades_prisionais.htm>. 
A situação encontrada ensejou, então, a instauração de inquérito civil pela $6^{a}$ Promotoria de Justiça da Cidadania para apurar as irregularidades que estariam ocorrendo naquela instituição, violando os direitos das pessoas ali mantidas sob internação.

Em 23 de dezembro de 2002, a Diretoria de Vigilância e Controle Sanitário da Secretaria da Saúde do Estado da Bahia havia realizado visita técnica ao HCTP, de cujo relatório extraíram-se as seguintes informações²:

- Superlotação: 469 internados (425 homens e 44 mulheres) para uma capacidade de 280 leitos.

- Insuficiência de pessoal: 206 servidores, dos quais 188 diretamente ligados à assistência ao cliente (auxiliar de enfermagem, assistente social, agente de presídios e outros).

- Baixo grau de limpeza hospitalar, sem pessoal treinado.

- Falta de roupas (de cama, de banho e pessoal) e baixo grau de limpeza e conservação das existentes.

- Farmácia: falta ou insuficiência de medicamentos. Dos 28 medicamentos psiquiátricos previstos, o hospital dispunha de apenas cinco.

- Existência de cela forte e de outros espaços restritivos/punitivos.

- Inexistência das Comissões de Ética Médica, de Controle de Infecção Hospitalar, de Prevenção de Acidentes, de Revisão de Óbitos e de Revisão de Prontuários.

Constatou-se ainda negligência em tratamentos clínicos, submetendo os pacientes a riscos de maior precarização do estado de saúde, com a instalação de deficiência física ou mesmo a ocorrência de óbitos (houve quase duas dezenas de mortes em menos de um ano).

Ao lado dessas graves deficiências nas condições de salubridade, higiene, segurança e nas atividades terapêuticas, havia irregularidades jurídico-processuais que contribuíam para a deterioração da vida e da saúde dos internos à espera de definições. Tais irregularidades terminavam levando à prisão perpétua várias das pessoas custodiadas.

Com efeito, o exame das fichas funcionais dos internos revelou muitas irregularidades: pessoas recolhidas há mais de ano, aguardando realização de exame de sanidade mental (o prazo legal é de até 45 dias); internos com medida de segurança cumprida, esperando a realização de exame de cessação de periculosidade; outros já submetidos a Exame de Sanidade Mental, recolhidos

(2) VIANA, I. O papel do Ministério Público na defesa do direito à saúde da pessoa com transtorno mental autoria de delito. 2007. Dissertação (Mestrado). Instituto de Saúde Coletiva, Universidade Federal da Bahia, Salvador, 2007. 
há mais de dois anos, aguardando decisões judiciais nos respectivos processos; pacientes cujos Exames de Cessação de Periculosidade indicaram a desinternação, mas que continuavam no hospital-prisão (uns porque aguardavam regularização processual-judicial, outros porque tinham perdido o contato com os seus familiares ou foram por estes abandonados); pacientes internados para cumprimento de medida de segurança, sem serem submetidos às revisões periódicas legalmente previstas ${ }^{3}$.

No início de 2003, havia seis internos que portavam Carta de Desinternação e Alvará de Soltura, mas permaneciam à espera de serem entregues aos seus familiares. Outros 29 (20 oriundos do interior) já haviam cumprido a medida de segurança imposta e ali permaneciam em condição de abandono sóciofamiliar. Mais 14 internos (12 do interior) encontravam-se com alta, porém sem respaldo sóciofamiliar para serem desinternados, uma vez que seus familiares resistiam ao seu retorno.

No que tange à situação social dos internos, verificou-se a exclusão de direitos básicos de cidadania. Quase a metade dos internos não tinha qualquer documento de identificação pessoal. Situação essa que obstrui o acesso a programas governamentais de um modo geral, a exemplo do Benefício da Prestação Continuada, instituído através da Lei Orgânica de Assistência Social - LOAS e, de modo específico, o acesso ao programa "De Volta Pra Casa", criado para propiciar ao portador de transtorno mental submetido a longos períodos de internação o retorno ao meio familiar ou a inserção em um programa de residência terapêutica, consoante a política de saúde mental em desenvolvimento no Brasil.

Enfim, o tratamento dispensado aos internos do HCTP-Ba, seja em termos de assistência à saúde, seja em termos de assistência jurídica, não respeitava os mínimos padrões de civilidade, além de ferir claramente dispositivos legais, tanto no âmbito da política de saúde, quanto na legislação penal.

Diante dessa constatação, o Ministério Público Estadual instaurou o Inquérito Civil n 04/2003, que ensejou a firmatura de um Termo de Ajustamento de Conduta para adequação do Hospital de Custódia e Tratamento do Estado da Bahia ao ordenamento jurídico e às diretrizes traçadas pela reforma psiquiátrica, tendo como signatários o Ministério Público do Estado da Bahia e as Secretarias de Justiça e Direitos Humanos e da Saúde do Estado da Bahia, através dos seus mais altos representantes.

O Termo de Compromisso e Ajustamento de Conduta estabeleceu uma série de condições, que abrangeram desde aspectos referentes à estrutura do prédio e seus equipamentos até a atenção à saúde, passando pela regularização das pendências judiciais.

(3) VIANA, op. cit. 


\section{BREVE EVOLUÇÃO HISTÓRICA DA ABORDAGEM LEGAL DOS LOUCOS INFRATORES}

As raízes do atual direito penitenciário podem ser encontradas na Escola Clássica, desenvolvida no século XVIII a partir das ideias de Cesare Becaria ${ }^{4}$, cuja obra principal aparece em 1764. Essa escola tem como princípio básico a crença de que o homem possui o livre arbítrio e, por isso, é legalmente responsável por seus delitos. A ação criminal é definida, enfatizando-se a liberdade e a responsabilidade moral e penal do indivíduo, assim como os efeitos dissuasórios da punição.

Um século depois, em 1876, Cesare Lombroso publica L'Uomo Delinquente, obra que funda a Escola Positiva, destacando o determinismo biológico da criminalidade, em vez da responsabilidade individual. Lombroso constrói uma teoria evolucionista, segundo a qual os criminosos são indivíduos que reproduzem, física e mentalmente, características primitivas do homem. Assim, seria possível identificar, através dos sinais anatômicos, aqueles que estariam, por hereditariedade, destinados à prática de condutas criminosas 5 .

Essa abordagem biologicista encontra, rapidamente, opositores. De acordo com Aragão $(1977)^{6}$, no III Congresso Internacional de Antropologia Criminal, realizado em Bruxelas no ano de 1892, o magistrado francês Gabriel Tarde defende o ponto de vista de que os comportamentos sociais e a identidade ou a similaridade social seriam os critérios básicos de definição da responsabilidade penal. Do mesmo modo, Lacassagne aponta como causa do crime o meio social, enfatizando que cada sociedade tem os criminosos que merece. A intervenção dos opositores, entretanto, não conseguiu diminuir a influência da Escola Positiva nas políticas de tratamento dos doentes mentais infratores.

Paralelamente à questão dos determinantes, discutem-se as formas de penalização das condutas criminosas. A Era Moderna testemunha, em particular, a transformação da pena, que passa do suplício do corpo para o da alma ${ }^{7}$. O paradigma contratual do Estado Moderno, construído com base na obra de Jean-Jacques Rousseau, justifica e legitima a pena privativa da liberdade.

Vale acrescentar que, naquela época, em pleno processo de acumulação do capital industrial, massas despossuídas, expulsas dos campos, vêm a constituir a miséria das cidades. Sem possibilidade de se adequarem ao sistema das fábricas, tornam-se um excedente incômodo. Os capitalistas temiam a nobreza que ainda controlava o poder de repressão social reservado ao Estado, mas

(4) BITENCOURT, C. R. Tratado de Direito Penal. São Paulo: Ed. Saraiva, 2008. p. 49.

(5) ibidem, p. 56.

(6) ARAGÃO, A.M.S. As Três Escolas Penais. São Paulo: Saraiva, 1977. p.122.

(7) FOUCAULT, M. Vigiar e Punir. nascimento da prisão. Tradução de Raquel Ramalhete. Petrópolis:

Ed. Vozes, 2004. p. 18. 
temiam também o contingente de miseráveis que representava uma ameaça as suas riquezas.

O encarceramento tinha um sentido simbólico, mas, dada a quantidade de miseráveis, não trazia resultado prático. Para controlar as massas, seria preciso diminuí-las, o que, em parte, se conseguiu com a emigração para a América. Todavia, a emigração não absorveu toda a massa populacional excluída do processo produtivo. E para os que permaneceram, o controle social encontrou dois caminhos: para os não culpáveis, a beneficência do asilo; e para os culpáveis, a institucionalização forçada dos cárceres, dentre estes, o manicômio.

Os caminhos do direito penal e da assistência aos loucos se entrecruzam e se confundem como alternativa para os excedentes sociais excluídos do novo modelo de produção que se implantava: o cárcere e o manicômio, que viriam a se constituir em dois grandes estigmas do Estado Moderno.

No final do século XVIII, a pena corporal chega, legalmente, ao seu fim. Surgem, então, os chamados sistemas penitenciários - controle social punitivo institucionalizado e centrado na restrição da liberdade ${ }^{8}$.

No curso desse processo, o tratamento reservado às pessoas com transtornos mentais que praticavam atos delituosos afasta-se do encarceramento coletivo com outros doentes mentais não delinquentes ou com criminosos em geral, enquanto se consolida o seu encarceramento exclusivo e compulsório, de caráter pretensamente terapêutico.

Com a Revolução Francesa, surge um novo enfoque social que impõe uma política de saúde mental, consolidada na lei de 1838, para regular o regime dos alienados. Com a substituição do poder do rei pelo poder da justiça e da administração pública, constitui-se um corpo de profissionais médicos responsável por enquadrar os indivíduos no novo estatuto do louco - o de doente -, reservando-lhes um estabelecimento especial, o asilo.

No Brasil, as primeiras instituições psiquiátricas surgiram em meio a um contexto de valorização social da "proteção à ordem" e da "paz social", atendendo aos protestos contra o livre trânsito de alienados pelas ruas das cidades. À época, o meio social era fortemente polarizado entre dois extremos: de um lado, uma minoria de senhores e proprietários e, de outro, a multidão de escravos e a massa indefinida e crescente de desocupados permanentes ou transitórios.

Os loucos engrossam essas levas de vadios e desordeiros nas cidades, arrastadas na rede comum da repressão à desordem, à mendicância, à ociosidade. Os doentes mentais são recolhidos aos porões das Santas Casas de Misericóridia, mas não recebem assistência médica. Seus delírios e suas agitações são reprimidos por espancamentos ou contenção física que pode

(8) ZAFfARONI, E.R; PIERANGELI, J. H. Manual de Direito Penal Brasileiro - parte geral. $6^{\mathrm{a}}$ ed. São Paulo: Revista dos Tribunais, 2006. p. 63. 
durar até a morte, causada por maus tratos, desnutrição e doenças infecciosas. A exclusão se manifesta como tendência central da assistência psiquiátrica brasileira já nos seus primórdios.

O primeiro Código Penal do Brasil foi sancionado em 16 de dezembro de 1830, pelo Imperador D. Pedro I, observando os preceitos da Escola Clássica do direito penal, segundo a qual a tipificação de um ato delituoso independia dos atributos pessoais de quem o praticava ${ }^{9}$.

Como a loucura, móvel do crime, punha em questão os pilares da doutrina clássica do direito, o Código Criminal do Império assim tratou o assunto no seu Art. 10: ... "não se julgarão criminosos:... $§ 2^{\circ}$ Os loucos de todo gênero, salvo se tiverem lúcidos intervalos e neles cometerem o crime".

Esse mesmo código dizia no Art. 12: "Os loucos que tiverem cometido crimes serão recolhidos às casas para eles destinadas, ou entregues às suas famílias, como ao juiz parecer mais conveniente". Naquela época, ainda não existiam asilos nem lugar específico para abrigar os loucos. Aos doentes mentais pobres, que vagavam pelas ruas, restavam as prisões e as Santas Casas ${ }^{10}$. Os doentes abastados eram entregues aos cuidados das respectivas famílias.

Com a inauguração, em 1852, no Rio de Janeiro, do primeiro asilo para doentes mentais, o Hospício D. Pedro II, e seguindo a determinação do Código Penal Imperial, os juízes passaram a ter para onde enviar os loucos infratores. Os alienistas, contudo, protestaram, sob o argumento de que a invasão dos asilos por criminosos comprometia o tratamento; então, organizaram um movimento para a construção de manicômios judiciários.

O Código Criminal do Império definia os loucos como inimputáveis e isentos de sanções penais. Para a constatação da alienação mental, os exames médicos periciais bastavam como provas legítimas e suficientes.

Essa legislação propiciava um grande número de absolvições, gerando insatisfações entre os magistrados, o que levou ao estabelecimento de limites à autonomia do perito, que passa à condição de assessor do juiz no processo.

O século XX se inicia, já sob o regime republicano, com os insanos delinquentes sendo colocados em áreas especiais dos asilos. O Decreto 132, de 23 de dezembro de 1903, estabelece normas para a internação dos alienados, proibindo a sua manutenção em cadeias públicas ou entre criminosos.

Em consequência desse decreto, foi instalada no Hospício D. Pedro II uma enfermaria destinada à internação dos alienados delinquentes e para

(9) CHALOUB, M. Introdução à Psicopatologia. Rio de Janeiro: Forense, 1981. p. 17.

(10) AMARANTE, P. Asilos, Alienados e Alienistas: Uma pequena história da psiquiatria no Brasil. In: AMARANTE, P. (org.) Psiquiatria Social e Reforma Psiquiátrica. $3^{\text {a }}$.Reimpressão, Rio de Janeiro: Ed. Fiocruz, 2008. p. 73-84. 
observação dos acusados suspeitos de alienação mental, fazendo surgir a "seção Lombroso", que funcionou até a criação do primeiro Manicômio Judiciário no Rio de Janeiro, em 1921.

Em 1940, um novo Código Criminal é sancionado. Pelos seus critérios, o crime contém um momento intelectivo - que se relaciona com a capacidade de entendimento - e um momento volitivo - relacionado com a capacidade de determinação. Para caracterizar um criminoso como inimputável, é suficiente a ausência de um dos elementos - a vontade ou o entendimento - em decorrência de doença mental ou desenvolvimento mental incompleto ou retardado.

As causas biológicas são as únicas capazes de suprimir a capacidade de entendimento e determinação, quando deixa de existir a responsabilidade e cabe ao perito sanar a dúvida, na qualidade de auxiliar do juiz, sobre a existência de insanidade mental. Nota-se que a Escola Positiva, de Lombroso, fundamenta o Código Penal republicano, assim como a Escola Clássica, de Becaria, havia fundamentado o Código Imperial.

Com esse novo código (1940) surge, no cenário jurídico brasileiro, a medida de segurança, visando, simultaneamente, propiciar o tratamento psiquiátrico adequado ao doente mental infrator e manter a paz social, através do encarceramento dos indivíduos considerados perigosos para a sociedade.

O Código Penal atualmente em vigor é o mesmo de 1940, com algumas modificações introduzidas em 1984. Em relação aos doentes mentais infratores, preceitua:

Art. 96: As medidas de segurança são: I - internação em hospital de custódia e tratamento psiquiátrico ou, à falta, em outro estabelecimento adequado; II - sujeição a tratamento ambulatorial;

Art. 97: Se o agente for inimputável, o juiz determinará sua internação. Se, todavia, o fato previsto como crime for punível com detenção, poderá o juiz submetê-lo a tratamento ambulatorial.

$\S 1^{\circ}$ : A internação ou tratamento ambulatorial será por tempo indeterminado, perdurando enquanto não for averiguada, mediante perícia médica, a cassação de periculosidade. O prazo mínimo deverá ser de 1 (um) a 3 (três) anos.

$\S 2^{\circ}$ : A perícia médica realizar-se-á ao termo do prazo mínimo fixado e deverá ser repetida de ano em ano, ou a qualquer tempo, se o determinar o juiz da execução.

$\S 3^{\circ}$ : A desinternação ou a liberação será sempre condicional, devendo ser restabelecida a situação anterior se o agente, antes do decurso de 1 (um) ano, pratica fato indicativo de persistência de sua periculosidade.

$\S 4^{\circ}$ : Em qualquer fase do tratamento ambulatorial, poderá o juiz determinar a internação do agente, se essa providência for necessária para fins curativos.

Como se percebe, esse tipo de internação compulsória pode se tornar perpétua, já que tem prazo mínimo, mas não tem limite máximo. E, em se 
tratando de doentes mentais, a deflagração do incidente processual atende a meros sinais e sintomas detectados por pessoas leigas em medicina, e o suposto infrator é internado no HCTP para a realização do Exame de Sanidade Mental.

A todo delinquente que o juiz presumir perigoso se impõe a aplicação da medida de segurança: se, no curso de sua execução, a perícia médico-psiquiátrica atestar a cessação da periculosidade latente do condenado, terá este o livramento condicional, que importará, se cumpridas as condições sem intercorrências até o termo final da medida aplicada, na revogação da medida de segurança. Caso contrário, isto é, persistindo os indícios de periculosidade, o delinquente permanecerá custodiado sob medida de segurança, cuja duração é condicionada à permanência do "estado perigosos" e, portanto, indeterminável de antemão. Por isso mesmo é que se diz não ter caráter punitivo, visando apenas ao fim de utilidade a que se pode chamar "cura social dos perigosos"11. A medida de segurança é aplicável aos irresponsáveis ou incapazes, desde que se apresente a sua periculosidade, isto é, a relevante probabilidade de retornar à prática de fatos previstos como crime.

A ciência penal denomina de "livramento condicional" a liberdade antecipada ao condenado que cumpre uma pena privativa de liberdade superior a dois anos, desde que atendidos os requisitos legais e sob condições judiciais. Esse benefício é extensivo ao sentenciado com medida de segurança, somente quando ocorrer a ausência ou cessação de periculosidade (Código de Processo Penal, Art. 710, II).

A cessação de periculosidade é aferida por meios subjetivos, através de indiciárias expressões de conduta, interpretando atitudes exteriorizadas, analogias ou sugestões de experiências em casos anteriores. Apesar de ser uma prognose sem critérios de certeza, é o único substrato a subsidiar o julgamento de concessão de liberdade condicional. Há que se considerar que a cessação de periculosidade não certifica a cura do doente mental, apenas aventa uma prognose da possibilidade de voltar a delinquir. Mesmo assim, a lei espera que o interno entenda e cumpra as condições impostas, sob pena de reinternação motivada por quebra de salvo-conduto.

Todavia, o advento da Constituição Federal de 1988, com os princípios da presunção da inocência, da dignidade da pessoa humana e do direito ao atendimento integral de saúde, põe em questão a medida de segurança.

O tratamento discriminatório aplicado aos doentes mentais autores de delitos aponta para a necessidade da revisão da política criminal que lhes é aplicada no que tange à atenção à saúde e à restrição da sua liberdade por tempo indeterminado, entre outros direitos de cidadania.

(11) HUNGRIA, N. Métodos e critérios para a avaliação da cessação de periculosidade. Revista Jurídica, ano 4, v.22, jul./ago., 1956. p.5 
Em 6 de abril de 2001, foi sancionada a lei $n^{\circ} 10.216$, que visou implantar um novo modelo de assistência à saúde mental, enfatizando a atenção de base comunitária, de maior potencial de reabilitação psicossocial do que o atendimento centrado na internação hospitalar. Encontra-se aí mais uma razão da necessidade de revisão da medida de segurança.

Vale acrescentar que a Lei n 9.099, de 1995 (em vigência há 15 anos, portanto!), que dispõe sobre os Juizados Especiais Cíveis e Criminais e dá outras providências, considera infrações penais de menor potencial ofensivo aquelas às quais a lei comina pena máxima não superior a dois anos. Esse benefício, contudo, não se estende ao agente infrator portador de doença mental, que sofre a aplicação de medida de segurança sob internação até em casos de delitos de dano e de ameaça.

Enfim, o tratamento dos doentes mentais infratores evolui, desde o início da Era Moderna, de uma concepção jurídica que considera inimputável o louco, já que não está em condições de exercer seu livre arbítrio, para outra que vê o louco infrator como portador de características biológicas que o levam à loucura e ao crime e, portanto, deve estar sujeito ao tratamento compulsório e à restrição de liberdade.

No vigente Código Penal brasileiro, a abordagem à questão das pessoas com transtornos mentais que cometeram delitos é orientada pela concepção biologicista e, em consequência, impõe uma dupla penalização, em desacordo com os atuais princípios constitucionais e de forma discriminatória, inclusive em relação a infratores que não sofrem de transtornos metais.

\section{A REFORMA PSIQUIÁTRICA E AS PESSOAS COM TRANSTORNOS MENTAIS QUE COMETERAM DELITOS}

Na esteira da implantação do Sistema Único de Saúde e sob o regramento constitucional que inseriu a dignidade da pessoa humana como fundamento da República, a Política Nacional de Saúde Mental foi consignada na agenda pública brasileira através da lei $n^{\circ} 10216$, de 2001.

A política de saúde mental define as linhas a serem desenvolvidas para oferecer assistência com maior potencial de reabilitação psicossocial às pessoas com sofrimento mental. Tem como premissa básica a desinstitucionalização do paciente, com ampliação da rede comunitária de cuidados e fortalecimento de iniciativas de organização de equipamentos que superem tanto o tratamento ambulatorial tradicional, que não favorece a criação de vínculos consistentes entre profissional de saúde e usuário, quanto a internação hospitalar prolongada, iatrogênica pelo isolamento social que promove. 
Assim, a reinserção social das pessoas com transtornos mentais, a partir da intervenção de serviços de atendimento no seio da comunidade, a exemplo dos Centros de Atenção Psicossocial - Caps -, constitui o eixo da reorientação psiquiátrica em vigor.

No processo de execução dessa política, o Ministério da Saúde publicou a Portaria $n^{\circ}$ 0052/2004, que instituiu o Programa de Reestruturação da Assistência Psiquiátrica Hospitalar no SUS - 2004, visando permitir uma transição do modelo hospitalocêntrico de assistência psiquiátrica para outro de base comunitária.

A referida portaria define uma classificação dos hospitais psiquiátricos, baseada no número de leitos contratados pelo SUS, com novos valores de remuneração das diárias hospitalares, que incorporam incentivos à qualificação do atendimento e à redução de leitos. Especificamente, a cada redução de 40 leitos, o hospital ganha um aumento no valor da diária paga pelo SUS.

Infeizmente, todas essas medidas de operacionalização dos princípios da reforma psiquiátrica não atingem os serviços voltados para a assistência aos doentes mentais infratores.

Os Hospitais de Custódia e Tratamento Psiquiátrico não integram o sistema de saúde, e sim o sistema penitenciário, como uma de suas unidades prisionais; portanto, não estão incluídos no Programa de Reestruturação da Assistência Psiquiátrica Hospitalar e, em consequência, não fazem parte do Sistema Único de Saúde e não recebem nenhum incentivo para a qualificação do atendimento ou para a redução de leitos. Os CAPS e os serviços de residência terapêutica, por sua vez, não preveem a atenção às pessoas com transtornos mentais que cometeram delitos.

De fato, o tratamento dessas pessoas continua como responsabilidade do sistema penitenciário e do Poder Judiciário, o que não seria talvez tão grave se a legislação penal fosse coerente com os princípios constitucionais da dignidade da pessoa humana e da cidadania e com as disposições da lei especial da reforma psiquiátrica.

Ocorre que o Código Penal vigente tem como fundamento a busca da identificação de um nexo de causalidade entre o estado mental e o crime praticado, através do critério biopsicológico ${ }^{12}$, claramente reducionista, de explicação da doença mental.

Além disso, a medida de segurança continua sendo a pedra de toque da legislação penal no que tange às pessoas com transtornos mentais. As modificações feitas no Código Penal, em 1984, não mudaram essa situação; apenas

(12) NUCCl, Guilherme de Souza. Código Penal Comentado, $5^{\mathrm{a}}$ Ed., São Paulo: Revista dos Tribunais, 2005. p. 236. 
estabeleceram o tratamento ambulatorial como alternativa ao internamento, mas ainda com prazo mínimo de duração definido (de um a três anos) e possibilidade de duração indefinida, mercê da cessação da periculosidade.

Assim, vários obstáculos inviabilizam o desenvolvimento da reforma psiquiátrica nessa área. A sua superação, contudo, é possível, dependendo, essencialmente, de uma tomada de posição da sociedade civil organizada e do aprofundamento de iniciativas governamentais que articulem as áreas da saúde pública e da justiça.

Em primeiro lugar, existe uma zona cinzenta em que convivem mal a repressão e o cuidado. $O$ mito da periculosidade parece arraigado ao senso comum, o que permite que o tratamento desses doentes continue sob a forma de segregação em estabelecimentos de internação e custódia, sem o mínimo respeito à dignidade humana.

Nesse sentido, o exemplo do Hospital de Custódia e Tratamento Psiquiátrico da Bahia é eloquente. Os inúmeros casos de abandono familiar podem ser indicadores da crença generalizada no mito da periculosidade ou na condição de subcidadãos dos doentes mentais infratores.

De modo similar, a negligência do cuidado à saúde e o descumprimento de várias determinações legais, patentes no caso do HCTP-Ba, são reveladores de um senso comum permissivo ao desrespeito à dignidade de certas pessoas: daquelas que sofrem de transtornos mentais e cometeram delitos.

Em segundo lugar, se, na teoria e na legislação sanitárias, evoluiu-se de uma concepção de isolamento dos doentes mentais em proteção da sociedade para outra concepção de respeito à dignidade humana e de inserção social das pessoas com transtornos mentais, na legislação penal, ao contrário, continua a prevalecer o tratamento que contempla o isolamento. A possibilidade de tratamento em regime ambulatorial, prevista e aplicável quando o delito cometido é apenado com detenção é ignorada.

Fundamentalmente, a periculosidade atribuída ao doente mental como condicionante da aplicação da medida de segurança na forma de internação sob custódia tem sido um obstáculo de difícil superação para a efetiva inclusão destes doentes no rol de sujeitos dos direitos que estão garantidos na Constituição Federal e, especialmente, consignados na lei da reforma psiquiátrica.

Ressalte-se que esses direitos, garantidos por princípios constitucionais que se constituem em fundamentos de valor axiomático que sustentam todo o ordenamento jurídico pátrio, ainda que de difícil conceituação formal, ante o seu caráter polissêmico, são, inequivocamente, inerentes à condição humana, direitos que homens e mulheres têm pelo simples fato de existirem. Portanto, deles não se podem excluir as pessoas com transtornos mentais, mesmo que tenham cometido delitos. 
Nesse sentido, o instituto da medida de segurança é um anacronismo que urge superar. É preciso rever as legislações penal e processual penal, não no sentido que tem sido costumeiro, de agravar as penas e a repressão, mas sim insistindo no caminho promissor de um processo civilizatório de humanização da sociedade e de promoção da paz social, objetivo maior do ordenamento jurídico, desde os primórdios da lei, consoante o contexto constitucional da atualidade.

Em terceiro lugar, o avanço da reforma psiquiátrica na área penal é obstaculizado pela incipiência, inclusive quantitativa, das unidades substitutivas da internação. São necessários não apenas CAPS e serviços de residências terapêuticas, mas ainda outras modalidades assistenciais com estruturas adequadas para desenvolver linhas de cuidados, capazes de inserir socialmente e de preservar a dignidade da pessoa humana que apresenta transtornos mentais e cometeu algum delito.

Há que se realizar um trabalho de sensibilização da sociedade no sentido de denunciar preconceitos e intolerâncias. A mobilização da sociedade civil, em torno da questão da atenção à saúde mental em geral, tem sido significativa. O passo a ser dado agora é o da inclusão dos doentes mentais infratores, os mais excluídos dos excluídos.

\section{CONSIDERAÇÕES FINAIS}

Este estudo demonstra que, objetivamente, a única função que cumprem o HCTP-Ba e - pode-se, provavelmente, generalizar - todos os manicômios judiciários é buscar manter a ordem, conforme os padrões sociais ${ }^{13}$, que, no Brasil do século XXI, parecem ainda admitir o desrespeito à lei, quando da sua aplicação aos excluídos socialmente.

Demonstra ainda, pelo relato do caso do Hospital de Custódia e Tratamento Psiquiátrico da Bahia, que a reforma psiquiátrica, assim como as reformas sociais, em geral, não dependem apenas de leis que as respaldem ou autorizem.

Apesar das conquistas constitucionais de direitos de cidadania, incluindo o direito social à saúde, e da lei específica sobre o cuidado à saúde mental, as pessoas com transtorno psiquiátrico que cometeram delitos continuam a ser tratadas como não cidadãs. As internações prosseguem a ser efetuadas em instituições com características asilares, em locais insalubres e isolados do convívio comunitário.

No âmbito jurídico brasileiro, por sua vez, não houve ainda qualquer movimento no sentido de alterar os dispositivos dos Códigos Penal e Processual

(13) GOFFMAN, E. Manicômios, Prisões e Conventos. Trad. Dante Moreira Leite. São Paulo: Perspectiva, 2001. p. 295. 
Penal, visando impedir as longas internações compulsórias como resposta jurídico-penal aos delitos cometidos por doentes mentais, em estabelecimentos fechados, distantes das famílias e do meio comunitário de origem. Além do mais, a prática judicial em nada se modificou. Os dispositivos da legislação penal que disciplinam a matéria continuam a respaldar as decisões judiciais, como se estivessem em consonância com a Constituição Federal vigente, quando estão, como se procurou demonstrar, em absoluta contradição, principalmente no que diz respeito ao princípio da dignidade da pessoa humana.

As condições sub-humanas e segregacionistas encontradas no Hospital de Custódia do Estado da Bahia e, possivelmente, em tantos outros espalhados no território brasileiro alertam para a necessidade de superação dos manicômios judiciários e a instituição de novos espaços de assistência à saúde dignos e humanizados, que possibilitem ao doente mental infrator o resgate da sua autonomia e a sua reinserção social.

Em última instância, é a sociedade como um todo que precisa superar crenças irracionais que têm provocado o aumento e a perpetuação do sofrimento de muitos e dificultado a instituição de padrões humanizados de convívio social.

\section{REFERÊNCIAS}

AMARANTE, P. Asilos, Alienados e Alienistas:Uma pequena história da psiquiatriano Brasil. In: AMARANTE, P. (org.) Psiquiatria Social e Reforma Psiquiátrica. $3^{a}$ Reimpressão, Rio de Janeiro: Ed. Fiocruz, 2008.

ARAGÃO, A.M.S. As Três Escolas Penais. São Paulo: Saraiva,1977.

BAHIA, Secretaria de Justiça, Direitos Humanos e Cidadania. Disponível em: <http://www.sjcdh.ba.gov.br/sap/unidades_prisionais.htm>. Acesso em: 23.04.2010.

BECCARIA, C. Dos Delitos e das Penas. Porto Alegre: Editora Martin Claret, 2002.

BITENCOURT, C. R. Tratado de Direito Penal. São Paulo: Ed. Saraiva, 2008.

CHALOUB, M. Introdução à Psicopatologia. Rio de Janeiro: Forense, 1981.

FOUCAULT, M. História da Loucura. Trad. José Teixeira Coelho Neto, São Paulo: Perspectiva. 2004.

NUCCI, Guilherme de Souza. Código Penal Comentado, $5^{\mathrm{a}}$ Ed. São Paulo: Revista dos Tribunais, 2005.

GOFFMAN, E. Manicômios, Prisões e Conventos. Trad. Dante Moreira Leite. São Paulo: Perspectiva, 1996.

HUNGRIA, N. Métodos e critérios para a avaliação da cessação de periculosidade. Revista Jurídica, ano 4, v. 22, jul./ago., 1956. 
VIANA, I. O papel do Ministério Público na defesa do direito à saúde da pessoa com transtorno mental autoria de delito. 2007. Dissertação (Mestrado). Instituto de Saúde Coletiva, Universidade Federal da Bahia, Slvador, 2007.

ZAFFARONI, E.R; PIERANGELI, J. H. Manual de Direito Penal Brasileiro - parte geral. $5^{\text {a }}$ Ed. São Paulo: Revista dos Tribunais, 2004. 